TP Periodica Polytechnica Chemical Engineering

59(3), pp. 168-173, 2015

DOI: $10.3311 /$ PPch.7582

Creative Commons Attribution (i)

RESEARCH ARTICLE

\section{Comparison the Soxhlet and Supercritical Fluid Extraction of Nettle Root (Urtica dioica L.)}

\author{
Kornélia Kőszegi ${ }^{1 *}$, Gyula Vatai ${ }^{1}$, Erika Békássy-Molnár ${ }^{1}$
}

Received 26 June 2014; accepted after revision 10 December 2014

\begin{abstract}
The leaves of stinging nettle (Urtica dioica L.) are used for medical purposes since centuries while the nettle roots are applied only in the last decades. According to the latest researches the root of nettle contains many important ingredients, for example scopoletin, sterols, fatty acids, polysaccharides, polyphenols, minerals, etc. The polyphenols have antioxidant effect, reduce the hematological disorders, but also have anti-cancer and anti-bacteriological effects. The H-donating ability expresses the antioxidant activity.

In this study two kinds of extraction techniques and three kinds of solvents have been applied. The extraction techniques were: Soxhlet extraction with 96\% ethanol, Soxhlet extraction with n-hexane and supercritical fluid extraction (SFE) with $\mathrm{CO}_{2}$. All the measurements and the analysises were repeated three times.

Comparing the yields of the three extraction methods it was established that the highest yield value was reached by Soxhlet extraction with ethanol. The Soxhlet extraction and the supercritical extraction has lower yield, the total polyphenol content and the H-donating ability of these extracts were low.
\end{abstract}

\section{Keywords}

Soxhlet extraction, supercritical fluid extraction, Stinging nettle roots, Total polyphenol content, H-donating ability

\footnotetext{
${ }^{1}$ Department of Food Engineering, Corvinus University of Budapest,

H-1118 Budapest, Menesi ut 44., Hungary

*Corresponding author, e-mail: nelli.koszegi@uni-corvinus.hu
}

\section{Introduction}

Medical plants are largely investigated nowadays, because they are natural products with biologically active organic compounds, which usually are not aggressive, and do not cause severe side effects. The medical herbs are applied in the folk therapy since centuries [1,2].

The stinging nettle (Urtica dioica L.) is a well-known herb, it can be found everywhere in Asia, Europe and in Hungary, as well. The nettle leafs are used since ancient times [3]. The most important effects of nettle are anti-cancer, anti-inflammatory, hematological impacts [4], antibacterial effect [5], they are used for treatment of diabetes [2], cardiovascular deceases [4], rheumatic and allergic conditions [3], etc.

In contrast with the widespread investigation of nettle leafs and flowers, the nettle roots are discovered only in the last decades [6,7].

The aim of this study was on one hand to investigate the total polyphenol content of the nettle root extract, because the polyphenols are main ingredients of the nettle [8]. On the other hand to determine the H-donating ability, it is the main indicator of the antioxidant ability of the material.

The measurement results of the three types extraction were compared: Soxhlet extraction with 96\% ethanol, Soxhlet extraction with $n$-hexane and supercritical fluid extraction (SFE) with $\mathrm{CO}_{2}$.

\section{Materials and methods}

\subsection{Row material}

Stinging nettle (Urtica dioica L.) roots were applied to gain valuable components. The roots were collected by the Fitodry Ltd at south of Hungary, than dried naturally.

The airborn dried roots were chopped into $1 \mathrm{~mm}$ size by Fritsch mill, than the characteristic particle size of the chopped nettle root and the uniformity factor of the conglomerate was determined with sieve analysis, using Retsch AS 200 device. The pore size of the vibrated sieves was $0,0.1,0.25,0.315,0.4$, $0.5,0.63,0.8$ and $1.0 \mathrm{~mm}$. The retained material on each sieve was measured by tare balance (Fig.1). 


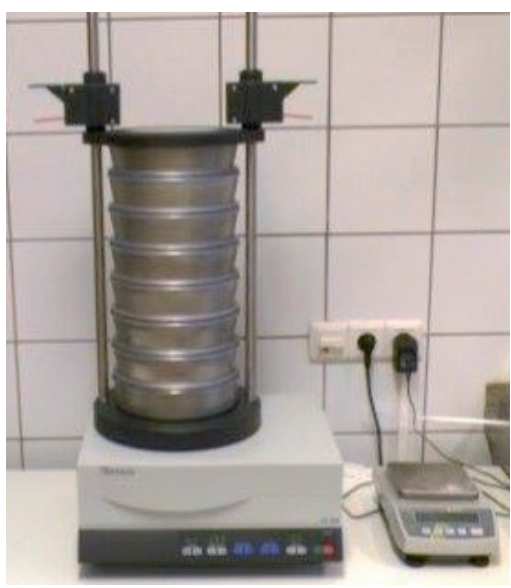

Fig. 1 Sieve shaker

Before the extraction measurements the dry matter of the naturally dried root pieces was determined in an owen at $104{ }^{\circ} \mathrm{C}$. The initial dry content of the input material was $91.07 \% \mathrm{w} / \mathrm{w}$.

In the extractions naturally dried and chopped stinging nettle roots were applied. Different extraction methods: Soxhlet and supercritical fluid extraction (SFE) and different solvents (ethanol, n-hexane, supercritical $\mathrm{CO}_{2}$ ) were applied.

\subsection{Extraction types}

In a Soxhlet extractor (Fig. 2) normally a solid material containing some of the desired compounds is placed inside a thimble made from thick filter paper, which is loaded into the main chamber of the extractor. The extraction solvent to be used is taken into a boiling distillation flask.

The solvent is heated to gain reflux. The chamber containing the solid material is slowly filled with hot solvent. Some of the desired compound will then dissolve in the hot solvent. When the Soxhlet chamber is almost full, the chamber is automatically empty by a siphon side arm, with the solvent running back down to the distillation flask. This cycle may be allowed to repeat many times, over hours or days.

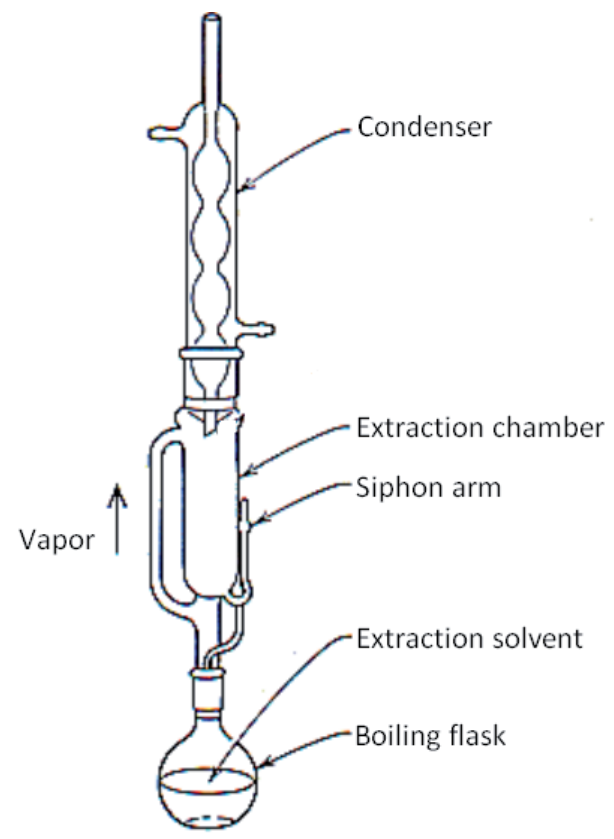

Fig. 2 Soxhlet extractor

In our case the extraction time was 14-15 hour, in each hour with 4 cycles. During each cycle, a portion of the soluble compounds were dissolved in the solvent. After many cycles the desired compounds were concentrated in the distillation flask.

Supercritical fluid extraction (SFE) is applied for herbs' separation since about 10-15 years, because it is suitable for careful, low temperature extraction of herbs' active ingredients.

As a solvent normally carbon dioxide is used, because it is cheap, not toxic, its critical temperature is very low (so substantial heat damage can be avoided), and at the end of the procedure it can be perfectly separated from the dissolved ingredients. The diffusivity of the supercritical fluid (SCF) is 100 times more than liquid diffusivity, and 1,000 - 10,000 times less than that of gases. Viscosity for SCF is similar with gases and 10 times less than that of liquids.

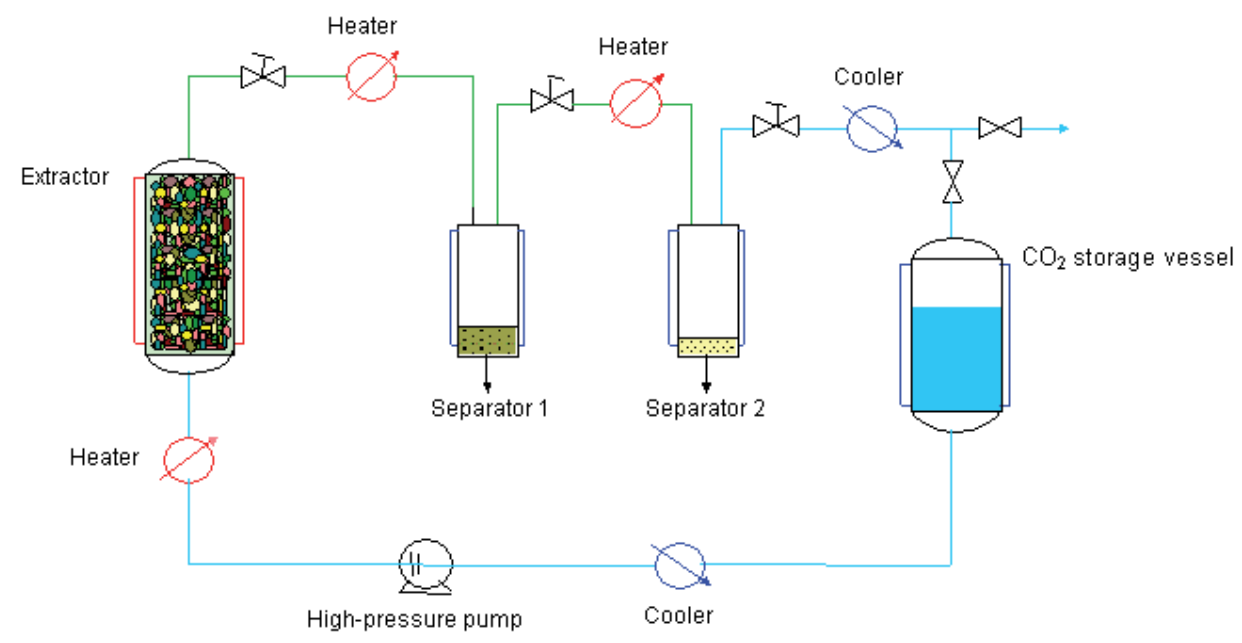

Fig. 3 Flowchart of supercritical fluid extraction (SFE) equipment 
The flowchart of the pilot SFE is shown in Fig. 3. The chopped root is placed into the extraction chamber, which can contain $1 \mathrm{~kg}$ material. The mobile phase, the liquid $\mathrm{CO}_{2}$ is pressed to the extractor with a high pressure pump. The solving power of SCF can be promoted by tuning temperature and pressure.

The basic principle of SFE is that in the extractor the feed material is contacted with the supercritical fluid, and soluble substances from the feed solve into the supercritical phase. In our case 300 bar pressure and $40{ }^{\circ} \mathrm{C}$ temperature was applied in the extractor. After the extraction the supercritical fluid, containing the dissolved substances, flows through a pressure reducing valve reaching 40 bar and $20^{\circ} \mathrm{C}$ in the first separator. The extract remains in separator 1 , while the $\mathrm{CO}_{2}$ passes through separator 2 and leaves the system. The stinging nettle does not contain volatile oil, therefore separator 2 was not used. The dissolution rate decreases in function of time, the extraction is less and less economic, after some hours - in our case after $3.5 \mathrm{~h}$ - the extraction has to be stopped.

The SCF may be recompressed to the extraction conditions and recycled.

\subsection{Analysis}

The total polyphenol content and the H-donating ability were determined by the literature $[9,10]$. The extracton yield was measured by tare balance.

\subsection{Total polyphenol content}

The total polyphenol content in the extracts was determined according to the literature $[9,10]$, by Campsec M501 spectrophotometer at $760 \mathrm{~nm}$, after half an hour incubation at room temperature. The reagent was the Folin-Ciocalteau solution, the reference was pyrogallol solution, identical background was distilled water. The concentration of the extract solution was $2.5 \mathrm{mg} / \mathrm{mL} 96 \%$ ethanol. From this sample $0.8 \mathrm{~mL}$ was mixed with $4 \mathrm{~mL}$ distilled water, $0.4 \mathrm{~mL}$ Folin-Ciocalteau reagent and $14.8 \mathrm{~mL} \mathrm{Na}_{2} \mathrm{CO}_{3}(29 \mathrm{~g} / \mathrm{L})$.

\subsection{H-donating ability}

The H-donating ability was determined by the method of Hatano et al. with some modification. [9]. 0.01 gram sample from the three different extracts was dissolved in $20 \mathrm{~mL}$ methanol. From each methanol solution $0.1,0.2,0.5,0.75$ and 1.0 $\mathrm{mL}$ were diluted with $2.5 \mathrm{~mL}$ DPPH solution. Before the measurement the absorbance of the DPPH solution was adjusted to 0.7-0.9. The control solution was methanol.

The absorbance of the solutions was measured after $30 \mathrm{~min}$ ute incubation at $517 \mathrm{~nm}$, by Camspec M501 spectrophotometer. The Inhibiting\% was calculated with the latter formula:

$$
\text { Inhibiting } \%=100 *\left(\mathrm{~A}_{\text {control }}-\mathrm{A}_{\text {sample }}\right) / \mathrm{A}_{\text {control }}
$$

where $\mathrm{A}_{\text {control }}$ is the absorbance of the DPPH solvent, $\mathrm{A}_{\text {sample }}$ is the absorbance of the sample.

The inhibition value of the different samples was compared at $30 \%$, which is that concentration value, when the inhibition reaches the $30 \%$.

\section{Results and discussion}

\subsection{Results of sieve analysis}

Table 1 contains measured points. Fig. 4 shows the average points of three parallel measurements.

The characteristic particle size and the uniformity factor were calculated by the Statistica program, using the RRBexpression [11]. The average particle size was $\mathrm{x}_{\mathrm{o}}=0.505 \mathrm{~mm}$, the uniformity factor was $n=2.00$.

The particle size distribution has some higher values below $0.15 \mathrm{~mm}$. It means the structure of nettle root is not homogenous, therefore lower $(\sim 0.15 \mathrm{~mm})$ diameter particles appear in the chopped nettle root.

\subsection{Results of Soxhlet extraction yields}

Soxhlet extractions were performed with naturally dried nettle root. Experimental data obtained by ethanol are collected in Table 2. The yield was defined as the dry matter content of the extract (DME) related to the initial dry matter content (DMC).

Table 1 Data of sieving

\begin{tabular}{|c|c|c|c|c|}
\hline Diameter of mesh sieve & Mass of sieves & Mass of sieves + nettle root & Mass of nettle root & Residual in percent $\%$ \\
\hline 0 & 362.9 & 373.4 & 10.5 & 10.50 \\
\hline 0.25 & 279.5 & 287.6 & 8.1 & 8.10 \\
\hline 0.4 & 366.4 & 382.9 & 16.5 & 16.50 \\
\hline 0.5 & 306.5 & 326.9 & 20.4 & 20.40 \\
\hline 0.63 & 381.9 & 398.1 & 16.2 & 16.20 \\
\hline
\end{tabular}




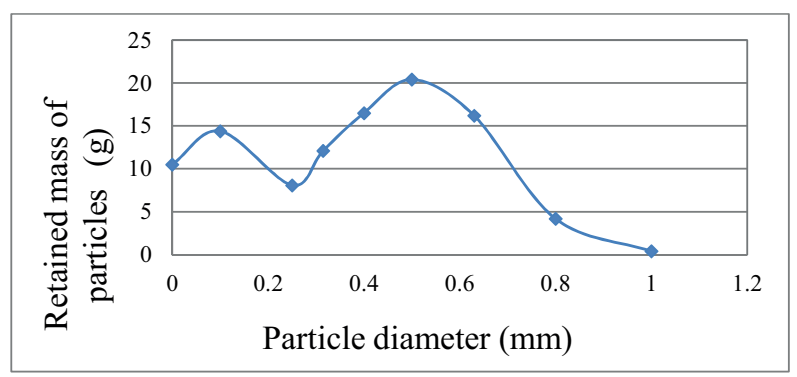

Fig. 4 Particle size distribution of chopped nettle root.

The average value of the yield was $14.14 \%$ in case of ethanol.

Table 3 shows the results with n-hexane as a solvent.

The n-hexane produced only $0.768 \%$ yield, which is much less, than that of the yield with ethanol.

\subsection{Results of supercritical extraction yields}

The supercritical fluid extraction experiments applied the same dried nettle roots as row material, and supercritical $\mathrm{CO}_{2}$ as solvent. The pressure in the extractor was 298-302 bar, the mass flow rate of $\mathrm{CO}_{2}$ was $\approx 7 \mathrm{~kg} / \mathrm{h}$. The pressure in the extractor varied less than $1 \%$, because of the instability of the pressure regulation.

Table 4 contains experimental data. As an example the steps of the SFE extraction at $\sim 300$ bar are detailed in this Table. The samples were taken every $\sim 35 \mathrm{~min}$. After each time section the dry matter content of the extract was measured in gram and calculated in $\%$. The used $\mathrm{CO}_{2}$ was noted as well. The $\mathrm{mCO}_{2}$ is the mass of the applied $\mathrm{CO}_{2}$ in one measurement step. The amount of the extract decreased in each time section, while the applied $\mathrm{CO}_{2}$ increased.

The input quantity of nettle root was $1.0034 \mathrm{~kg}$, and the dry matter content of it was $0.914 \mathrm{~kg}$. The extract was collected in separator 1 , its value was expressed in $\mathrm{kg}$, and in percent related to the initial dried root.

Fig. 5 presents the yield of SFE extract in percent as a function of the applied $\mathrm{CO}_{2}$, at 300 bar pressure.

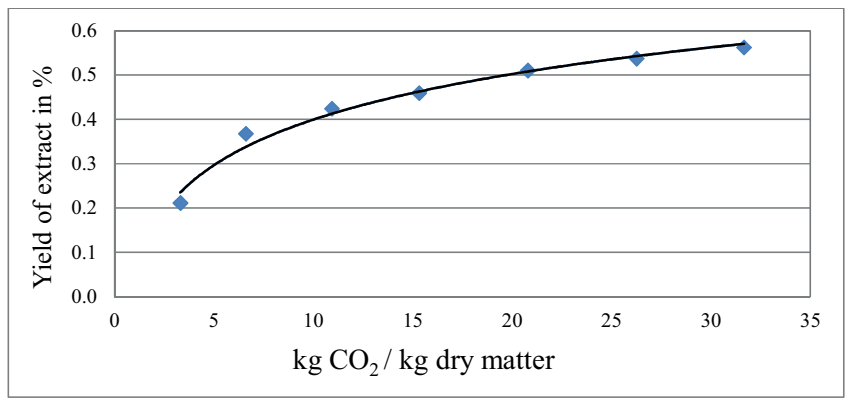

Fig. 5 Yield of SFE extracts in function of applied $\mathrm{CO}_{2}$ at 300 bar pressure

Table 2 Soxhlet extraction data of dried nettle roots using ethanol $96 \%$

\begin{tabular}{|c|c|c|c|c|}
\hline $\begin{array}{l}\text { Weight of dried nettle root } \\
\text { gram }\end{array}$ & $\begin{array}{l}\text { Dry matter content of dried nettle root } \\
\text { DMC } \\
\text { gram }\end{array}$ & $\begin{array}{l}\text { Dry matter content of extract } \\
\text { DME } \\
\text { gram }\end{array}$ & $\begin{array}{c}(\mathrm{DME} / \mathrm{DMC}) * 100 \\
\text { yield } \\
\%\end{array}$ & $\begin{array}{c}(\mathrm{DME} / \mathrm{DMC}) * 100 \\
\text { average yield } \\
\%\end{array}$ \\
\hline 19.81 & 18.16 & 2.53 & 13.90 & \multirow{3}{*}{14.14} \\
\hline & & & & \\
\hline 20.13 & 18.46 & 2.65 & 14.38 & \\
\hline
\end{tabular}

Table 3 Soxhlet extraction data of dried nettle roots using n-hexane

\begin{tabular}{|c|c|c|c|c|}
\hline $\begin{array}{c}\text { Weight of dried nettle root } \\
\text { gram }\end{array}$ & $\begin{array}{l}\text { Dry matter content of dried nettle root } \\
\qquad \begin{array}{c}\text { DMC } \\
\text { gram }\end{array}\end{array}$ & $\begin{array}{l}\text { Dry matter content of extract } \\
\text { DME } \\
\text { gram }\end{array}$ & $\begin{array}{c}(\mathrm{DME} / \mathrm{DMC}) * 100 \\
\text { yield } \\
\%\end{array}$ & $\begin{array}{c}\text { (DME/DMC)*100 } \\
\text { average yield } \\
\%\end{array}$ \\
\hline 22.4170 & 20.44 & 0.149 & 0.728 & \multirow{2}{*}{0.768} \\
\hline 20.6072 & 18.77 & 0.152 & 0.808 & \\
\hline
\end{tabular}

Table 4 Supercritical extraction steps

\begin{tabular}{|c|c|c|c|c|c|c|}
\hline \multirow{2}{*}{ Measurements } & \multirow{2}{*}{$\begin{array}{c}\text { Time sections } \\
\min \end{array}$} & \multirow{2}{*}{$\begin{array}{c}\mathrm{mCO}_{2} \\
\mathrm{~kg}\end{array}$} & \multicolumn{3}{|c|}{ Dry matter content of extract } & \multirow{2}{*}{$\begin{array}{c}\text { Used } \mathrm{CO}_{2} \\
\mathrm{~kg} \mathrm{CO}_{2} / \mathrm{kg} \text { dry } \\
\text { matter }\end{array}$} \\
\hline & & & kg & $\%$ & $\sum \%$ & \\
\hline 1. & 26 & 3.028 & $1.93 * 10^{-3}$ & 0.211 & 0.211 & 3.313 \\
\hline 2. & 26 & 3.004 & $1.43 * 10^{-3}$ & 0.156 & 0.367 & 6.600 \\
\hline 3. & 34 & 3.962 & $0.52 * 10^{-3}$ & 0.057 & 0.424 & 10.934 \\
\hline 4. & 34 & 4.015 & $0.32 * 10^{-3}$ & 0.035 & 0.459 & 15.327 \\
\hline 5. & 43 & 4.990 & $0.47 * 10^{-3}$ & 0.051 & 0.510 & 20.787 \\
\hline 6. & 43 & 5.016 & $0.25 * 10^{-3}$ & 0.027 & 0.537 & 26.265 \\
\hline sum & 206 & 24.015 & $4.92 * 10^{-3}$ & 0.537 & & 31.663 \\
\hline
\end{tabular}


The yields of the above mentioned SFE extraction steps at 300 bar are shown in Fig.5. The samples were taken every $35 \mathrm{~min}$. In function of time the extraction is less and less economic, because the increase of yield slows down.

\subsection{Comparison of polyphenol contents and $\mathrm{H}$-donating abilities of the three types of extracts}

To compare the quality of the three types of extracts, total polyphenol content and H-donating ability were determined.

In Fig. 6 the polyphenol content is shown, expressed in pyrogallol equivalent $\%$. As it can be seen, much more polyphenols were detected with Soxlet extraction using ethanol, than with Soxhlet using n-hexane, and more than in the SFE.

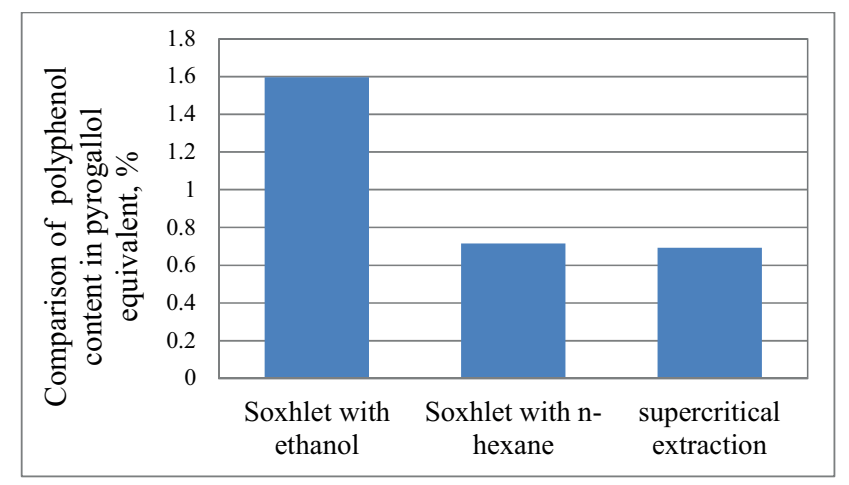

Fig. 6 Comparison of polyphenol content expressed in pyrogallol, mg/mL

The H-donating ability was compared at 30\% inhibition value (Fig.7). If the concentration of the extract is low - the $30 \%$ concentration was reached at low extract value - than the H-donating ability is high.

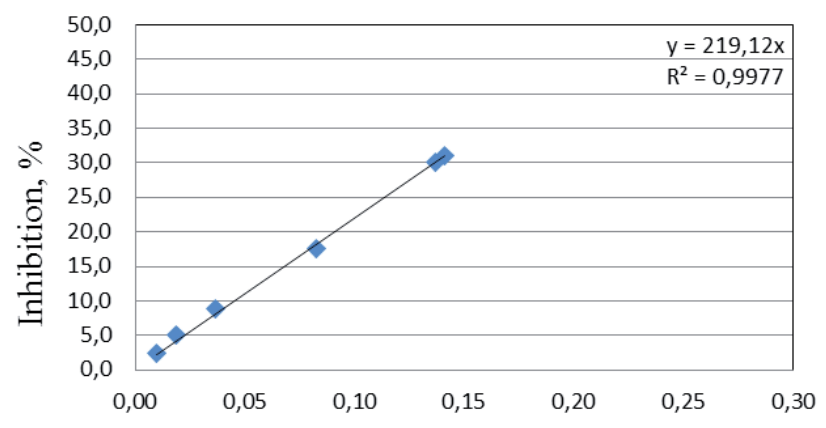

Concentration of extract solution, $\mathrm{mg} / \mathrm{mL}$

Fig. 7 H-donating ability of the extract, SFE 300 bar

Figure 8 presents the H-donating ability of the three extracts. In case of Soxhlet extraction with $96 \%$ ethanol, the best H-donating ability was measured.

The Soxhlet extraction with n-hexane and the supercritical extraction produced lower H-donating ability than the Soxhlet extraction with ethanol.

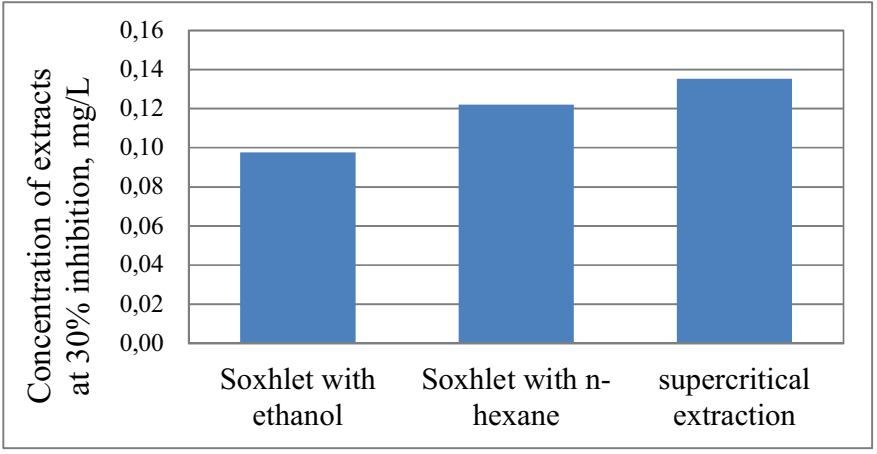

Fig. 8 Concentration of extract at $30 \%$ inhibition, $\mathrm{mg} / \mathrm{mL}$

\section{Conclusion}

Extraction of nettle root was investigated by different methods and solvents. Comparing the experimental results the next attributes were established:

In case of Soxhlet extraction with $96 \%$ ethanol the polyphenol content, expressed in pyrogallol equivalent, was $1.6 \%$, while the above mentioned value in case of Soxhlet extraction with n-hexane and supercritical fluid extraction was only the half of it, in both case about $0.7 \%$. It seems, the ethanol is the best solvent in our case to reach the highest polyphenol yield.

The H-donating abilities of the extracts of stinging nettle root were low in all the three extraction types, the concentration at $30 \%$ inhibition changed between $0.095-0.135 \mathrm{mg} / \mathrm{L}$. If the H-donating ability is high, than the material is proper for the reduction of free radicals in the human body. The highest concentration of extract - means the lowest DPPH value - was achieved using SFE. It suggests that this extract practically does not have inhibition effect, or contributes to the formation of free radicals. The understanding of this unusual fact will be the aim of the next experiments.

The particle size distribution shows, the nettle root is not a homogeneous material.

To sum the results: The SFE is not a proper method for the removal of polyphenols and to produce high H-donating ability, some other constituents of the stinging nettle root have to be tested. The extract of the Soxhlet extraction with ethanol or n-hexane contains the unpleasant solvents, which have to be separated, while the carbon dioxide from the SFE extract can be removed easily.

\section{Acknowledgements}

The authors would like to express their acknowledgement to Prof. Bela Simandi, Assoc. prof. Edit Szekely and Szabina Plander PhD student (Budapest University of Technology and Economic) for the help in experimental planning and their valuable advices. At the same time the authors thank the Hungarian National Scientific Foundation TÉT 10-1-2011-0072 and, OTKA K68596 for the financial support. 


\section{References}

[1] Di Lorenzo, C., Dell'agli, M., Badea, L., Dima, E., Colombo, E., Sangiovanni, P., Restani, E., Bosisio, E. "Plant food supplements with anti-inflammatory properties: A Systematic Review (II)." Critical Reviews in Food Science and Nutrition. 53 (5). pp. 507-516. 2013. DOI: 10.1080/10408398.2012.691916

[2] Afiti, F. U., Kasabari, V. "Pharmacological and phytochemical appraisal of selected medicinal plants from Jordan with claimed antidiabetic activities." Scientia Pharmaceutica. 81 (4). pp. 889-932. 2013. DOI: $10.3797 /$ scipharm.1212-20

[3] Upton, R. "Stinging nettles leaf (Urtica dioica L.). Extraordinary vegetable medicine." Journal of Herbal Medicine. 3 (1). pp. 9-38. 2013. DOI: 10.1016/j.hermed.2012.11.001

[4] Ozcan, C., Yaman, M. "Determination of kaempferol in rosa canina, Urtica dioica, terebinthina chica and portulace oleracea by HPLC-MS." Asian Journal of Chemistry. 25 (17). pp. 9758-9762. 2013. DOI: 10.14233/ajchem.2013.15311

[5] Dar, S. A., Ganai, F. A., Yousuf, A. R., Balkhi, M. U. H., Bhat, T. M., Sharma, P. "Pharmacological and toxicological evaluation of Urtica dioica." Pharmaceutical Biology. 51 (2). pp. 170-180. 2013. DOI: $10.3109 / 13880209.2012 .715172$
[6] Sajfrtova, M., Sovova, H., Opletal, L., Bartolova, M. "Near-critical extraction of beta-sitosterol and copoletin from stinging nettle roots." Journal of Supercritical Fluids. 35. pp. 111-118. 2005.

DOI: 10.1016/j.supflu.2004.12.008

[7] Nencu, I., Istudor, V., Ilies, D.-C., Radulescu, V. "Preliminary research regarding the therapeutic uses of Urtica dioica L. Note ii. The dynamics of accumulation of total phenolic compounds and ascorbic acid." Farmacia. 61 (2). pp. 276-283. 2013.

[8] Otles, S., Yalcin, B. "Phenolic compounds analysis of root, stalk, and leaves of nettle." The Scientific World Journal. pp. 1-12. 2012. DOI: $10.1100 / 2012 / 564367$

[9] Plander, S., Gontaru, L., Blazics, B., Veres, K., Kery, A., Kareth, S., Simandi, B. "Major antioxidant constituents from Satureja hortensis L. extracts obtained with different solvents." European Journal of Lipid Science and Technology. 114 (7). pp. 772-779. 2012. DOI: 10.1002/ejlt.201100273

[10] European Pharmacopocia $8^{\text {th }}$ Edition

[11] Shan, G., Igarashi, K., Noda, H., Ooshima, H. "Production of large crystals with a narrow crystal size distribution by a novel WWDJ batch crystallizer." Chemical Engineering Journal. 85 (2-3). pp. 161-167. 2002. DOI: 10.1016/s1385-8947(01)00153-X 